\title{
"NO OLHO DO FURAÇÃO”: A CONSTRUÇÃO PROJETO DE ISOLAMENTO SOCIAL FRENTE AO COVID-19, EM UM GRUPO INDÍGENA NA AMAZÔNIA
}

\author{
Petrônio Lauro Potiguar Junior ${ }^{1}$
}

\begin{abstract}
RESUMO
Expomos aqui este relato de experiência, fruto de uma viagem de cinco meses de pesquisa de campo na aldeia Mapuera, onde vivem vários grupos indígenas denominado genericamente de "Etnia Wai Wai", na cidade de Oriximiná, no noroeste do Pará, por conta da fase final da tese de doutorado que está em curso. Apresentamos aqui os momentos de angustias e inquietações vividos pelo autor desse relato e indígenas nesse local, nas primeiras manifestações da pandemia da Covid-19, denominado aqui de "olho do furacão", em março de 2020.Tal experiência nos direcionou ao seguinte questionamento: como antropólogo poderia contribuir em contexto de pandêmico em grupos indígenas, em especial, em Mapuera? A partir dessa pergunta, articulações foram feitas envolvendo cacique geral, lideranças, Conselho de Saúde da Mapuera, lideranças da igreja evangélica local, professores e profissionais da saúde que prestam serviço no local pela Fundação Ovídio Machado, frente ao Distrito Sanitário Guamá Tocantins- DSEI-GUATOC, incidido na elaboração de um projeto de isolamento social. Até a primeira quinzena de junho de 2020, momento da saída de campo, o referido projeto não tinha sido usado, pois nenhum caso de covid-19 acometera qualquer indígena no local, mas somente atingido alguns deles que estavam fora desse espaço, como na cidade de Belém, Santarém e Oriximiná, inclusive com óbito. Também notícias dão conta que, apesar de não adesão ao "projeto de Isolamento Social" pelo DSEIGUATOC, sua produção serviu de parâmetro para a feitura de um plano de proteção à equipe de saúde e aos indígenas do local, revelando um dos objetivos dessa proposição, inspirar ações de políticas públicas em tempos de pandemia para a proteção dos povos indígenas na Amazônia, independentemente de quem quer que seja.
\end{abstract}

Palavras-Chave: Covid-19. Isolamento. Antropologia.

\section{"IN THE EYE OF THE HURRICANE": THE DEVELOPMENT OF THE SOCIAL ISOLATION PROJECT IN FRONT OF THE COVID-19, IN A INDIGENOUS GROUP IN AMAZONIA}

\begin{abstract}
Here we expose this experience report, the result of a journey of five months of field research in the village Mapuera, where several indigenous groups live, generically called "Wai Wai Ethnicity", in the city of Oriximiná, northwest of the state of Pará, because of the final phase of the doctoral thesis that is underway. Here we present the moments of distress and concerns experienced by the author of this report and native people in this place, in the first manifestations of the Covid-19 pandemic, here denominated "eye of the hurricane", in March 2020. This experience leads us to the following question: How could an anthropologist help in the pandemic context that affects indigenous groups, especially in Mapuera? From that question, articulations were made involving the cacique chief, leadership, Mapuera Health Council, leaders of the local evangelical church, teachers and health professionals who provide service on the scene by Ovídio Machado Foundation, in front of the Guamá Tocantins- DSEI-GUATOC Sanitary District, focused on the development of a social isolation project. Until the first half of June 2020 , moment of field departure, the referred project had not been used, since no case of Covid-19 had

1 Doutorando em Sociologia e Antropologia/PPGSA UFPA; Mestrado em Agricultura Familiar e Desenvolvimento Sustentável. Graduado em Ciências Sociais, com ênfase em Antropologia. Já foi bolsista do Museu Paraense Emilio Goeldi. É professor Efetivo da Universidade do Estado do Pará-UEPA, no Centro de Ciências Sociais e da Educação. Realiza estudos sobre povos indígenas, especificamente a saúde/doença/cura e participa de grupos de estudo credenciado pelo CNPQ e possui texto e orienta trabalhos sobre a temática mencionada. E-mail: ppotiguar@yahoo.com.br.
\end{abstract}


affected any indigenous in the place, but only reached some of them who were outside that space, as in the city of Belém, Santarém and Oriximiná, including death. Also news reports that, despite the nonadherence to the "Social Isolation project" by the DSEI-GUATOC, its production served as a parameter for the development of a protection plan for the health team and the native people of the place, revealing one of the goals of this proposition: Inspire public policy actions in times of pandemic to protect indigenous peoples in the Amazonia, regardless of whoever they are.

Keywords: Covid-19. Isolation. Anthropology.

Data de submissão: 15.04 .2021

Data de aprovação: 02. 05. 2021

\section{O LOCAL DA EXPERIÊNCIA}

As Terras Indígenas - TI Nhamundá-Mapuera e Trombetas-Mapuera, estão localizadas na região norte do Brasil, Amazônia Setentrional, na fronteira tríplice dos Estados do Pará, Amazonas e Roraima, sendo o conjunto cortado ao meio pela linha do Equador. Segundo Cardozo e Do Vale Junior (2012), ambas TI's somam uma área de 5.020.418 ha, das quais 3.970.898 ha. Pertence à TI Trombetas-Mapuera e 1.049.520 ha. a TI Nhamundá-Mapuera. Nesta última área se localiza, locus dessa experiência, a aldeia Mapuera, conforme demonstra o mapa.

Figura 1 - Localização da Terra Indígena Nhamundá Mapuera, em vermelho

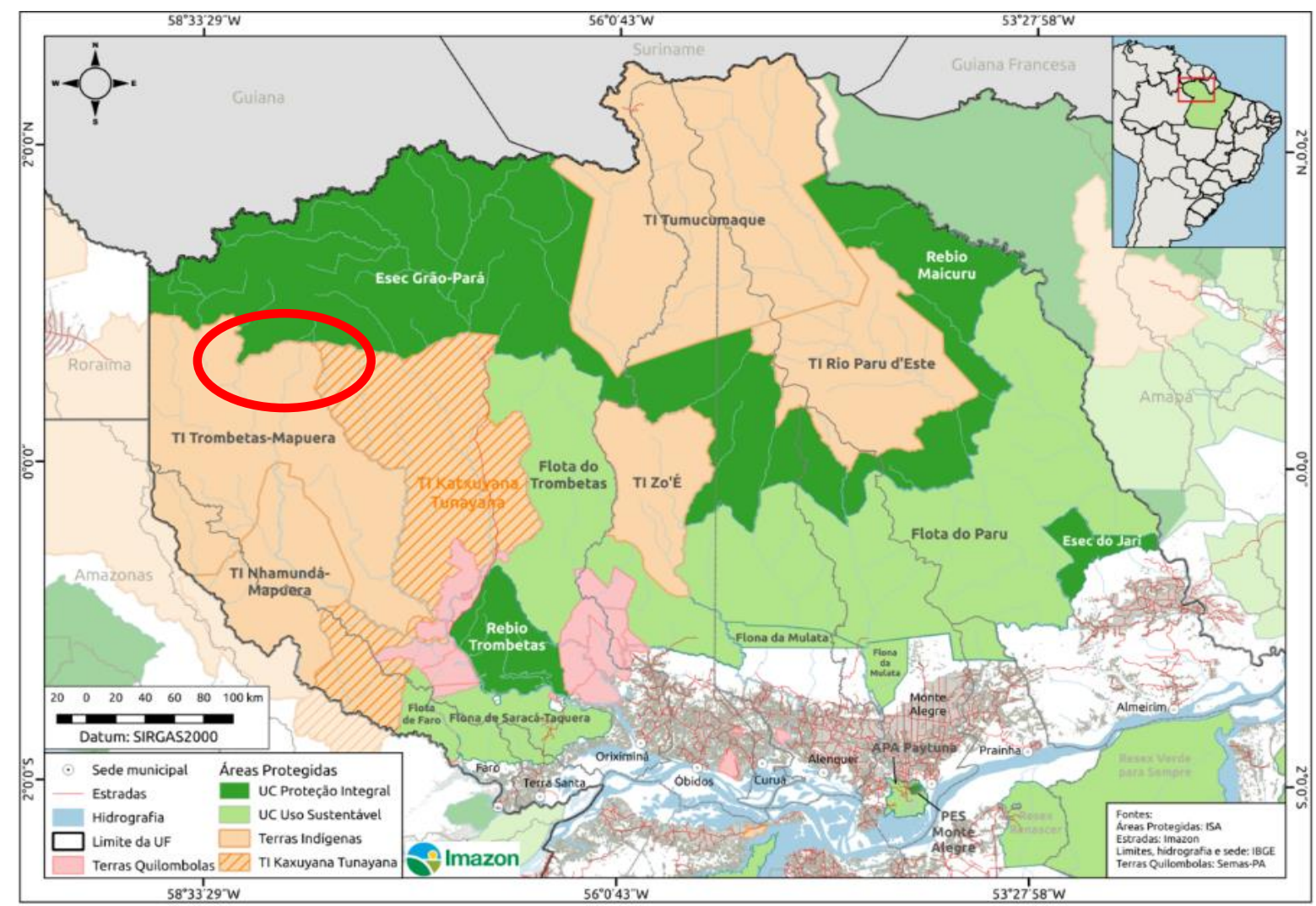

Fonte: Instituto Socioambiental - ISA.

A aldeia Mapuera faz parte do conjunto das Terras Indígenas Nhamundá-Mapuera, na Amazônia Setentrional, próxima à fronteira entre o Estado do Pará e do Amazonas, às margens do rio Mapuera, afluente/ formador do Rio Trombetas. Nesse local habitam aproximadamente 
1055 indígenas, conforme o Instituto de Socioambiental - ISA, dentre os quais encontram-se diversas etnias que fazem parte do complexo cultural Tarumã-Parukoto, sendo elas: Wai Wai, Katuena, Hixkaryana, Mawayana, Xowyana, Tikyana, Xereu, Tunayana, Kamarayana, Yaipîyana, Parîkwoto, Pianokoto, Tirió, Aramayana, Okomoyana e Caruma Wapixana. Mas todos que lá vivem se autodenominam "Wai-Wai² (CARDOZO e VALE JUNIOR:2012; QUEIROZ, 2008; QUEIROZ:1999; QUEIROZ e GIRARDI, 2012).

Estivemos em Mapuera por aproximadamente cinco meses, por conta da última pesquisa de campo para o Doutorado que o autor realiza no Programa de Pós Graduação em Sociologia e Antropologia na Universidade Federal do Pará - PPGSA/UFPA. Aqui será relatado os caminhos trilhados na pesquisa de campo, antes do início da pandemia Covid-19 ${ }^{3}$ - denominada aqui de "olho do furacão" - no Brasil, em fevereiro de 2020, até sua presença no Estado do Pará, em março do mesmo ano. Mostramos aqui como fora vivenciada a ameaça dessa pandemia, em Mapuera, a partir dos dramas pessoais e dos indígenas que ali vivem, somado a elaboração do projeto de isolamento social até a saída do autor deste relato desse local, em meados de junho de 2020.

Expor os caminhos trilhados junto com lideranças e a equipe de saúde para elaboração de um projeto de isolamento social, bem como, a expertise de todos frente a possibilidade de entrada de indígenas para essa aldeia diante da pandemia que se alastrava pelo país, foi a forma de socializar essa experiência, revelando seus limites e perspectivas pelas particularidades ali existentes. A maioria desses indígenas eram oriundos das cidades de Belém, Santarém e Oriximiná, onde a primeira e a segunda estavam com casos de Covid-19 e óbitos confirmados. Oriximiná, a sede municipal da Mapuera não possuía nenhum registro dessa doença, nesse momento da pesquisa, mas inspirava cuidados pela velocidade em que a pandemia avançava e os cuidados necessário para seu enfrentamento, tornando-se, assim, o foco deste relato.

Esse relato de experiência foi fruto da coleta de dados em campo para doutorado, cujo método etnográfico, foi sua base do início ao fim da pesquisa. Aqui o recorte temporal se direciona para o início da Covid-19, em março de 2020, no Estado do Pará, culminando com a saída do autor de campo, em junho do mesmo ano. As conversas formais e informais com lideranças indígenas, profissionais de saúde e da educação, permitiram vivenciar experiências diversas em Mapuera, inclusive a aqui relatada, materializada na exposição de um projeto de isolamento social cuja nuances serão reveladas a partir de agora.

\section{A PESQUISA DE CAMPO E O COVID-19: “UM INIMIGO INVISIVEL"}

No momento de nossa saída de Belém-Oriximiná-Cachoeira Porteira-Aldeia Mapuera ${ }^{4}$, no início de fevereiro de 2020, as notícias sobre coronavírus e a doença COVID-19 era de sua

\footnotetext{
${ }^{2}$ A denominação genérica de "Wai Wai" dos indígenas na aldeia Mapuera, se dá pelo processo histórico de surgimento do local. Mas no decorrer dos deslocamentos, os intercasamentos e a busca constante por indígenas isolados para serem convertidos ao evangelho protestante, outras etnias se somaram aos Wai Wai, mas o predomínio étnico Wai Wai, tornou essa a língua mais falada nas aldeias. Além disso acordos internos fizeram com que os indígenas da Mapuera fossem nominados de "Etnia Wai Wai" visando garantir direitos e políticas públicas de saúde, educação de forma diferenciada.

${ }^{3}$ Respeitando o tempo e os debates, percebe-se que ora falava-se em "Coronavirus", ora em "Covid-19”. Isso se deu pelas incertezas e familiaridade com categorias veiculadas pelos meios de comunicação sobre esse vírus/doença, cuja a base de referência era a Organização Mundial de Saúde- OMS. "Covid-19”, diz respeito à doença oriunda do vírus denominado de "Coronavirus" que surgiu primeiramente em 2002, na China e depois, em 2012, em alguns países Árabes. Dessa forma, Covid, somado ao número 19, diz respeito a demarcação do tempo em que ele se apresenta, na contemporaneidade, o ano de 2019, em sua nova configuração. (Fonte: https://coronavirus.saude.gov.br: consultado em 30 de março 2021).

${ }^{4}$ Para ter acesso a aldeia Mapuera, inicia-se a viagem saindo de Belém, via aérea, para a cidade de Santarém, em uma hora. Dessa cidade, via fluvial, por três horas e meia, chego até a cidade de Oriximiná. A partir de Oriximiná, o deslocamento até Cachoeira Porteira, se efetiva por barco, por dezessete horas. De lá, sigo para a aldeia Mapuera,
} 
ocorrência somente na China. Passados dias, a pandemia se alastrava pela Itália, Espanha, Inglaterra. Em seguida, chegava nos Estados Unidos da América. Final de fevereiro e início de março, desse mesmo ano, a pandemia atinge a América Latina e o Brasil, até chegar no Estado do Pará, na segunda quinzena de março do ano em tela.

Na Mapuera, nos encontrávamos imerso na pesquisa: registrando o cotidiano no diário de campo; circulando pela aldeia; conversando informalmente com as pessoas, realizando entrevistas e registrando imagens. Quando nos demos conta, já se faziam trinta e cinco dias no local. Sempre procurávamos nos atualizar com notícias, via televisão e internet ${ }^{5}$. Nesse interim, o diretor da Organização Mundial de Saúde - OMS Tedros Adhanom anunciava, em final de fevereiro de 2020, que estávamos frente a uma Pandemia, já que a Covid-19 ultrapassava e avançava em vários continentes, inclusive na América Latina.

A notícia sobre a chegada da Covid-19 no Brasil se espalhou, dando início a contaminação no país, sendo a cidade de São Paulo a primeira capital a registrar uma contaminação e, posteriormente, o óbito. Posteriormente, essa cidade tornou-se o epicentro da pandemia no país, seguido pelo estado do Amazonas, acendendo o sinal de alertas, no Pará, pela proximidade geográfica.

No Pará, em março de 2020, o primeiro caso de Covid-19 foi anunciado. As preocupações nos rondavam em Mapuera, pois, na mesma força que corriam as notícias, o vírus avançava na capital paraense, Belém, e no interior. As notícias davam conta que a Covid-19 estava em todos os lugares, nos levando a pensar que, sua chegada na aldeia, seria uma questão de tempo. Além disso, os deslocamentos de indígenas Mapuera-Oriximiná e vice-versa, eram constantes. Somado a isso, muitos desses indígenas estudavam em diversas cidades e manifestavam o desejo de retornar para aldeia ${ }^{6}$, aumentado a preocupação de todos por conta do cenário pandêmico que nos encontrávamos

Os trajetos pelo rio Mapuera, via canoa e barco, para acessar a aldeia de mesmo nome, tornou-se limitado, consequência de casos de Covid-19 em Santarém, Óbidos e Oriximiná7. Diante disso, o prefeito do município-sede - Oriximiná - decreta estado de emergência: aulas foram suspensas e limitações de deslocamentos municipais e intermunicipais foram efetivadas ${ }^{8}$. No entanto, uma medida não fora obedecida na aldeia, a realização dos cultos evangélicos 9 .

Com o passar dos dias, as restrições de acesso à Belém do Pará, onde residíamos, e Mapuera, local de desempenho dessa pesquisa, foram se sedimentando. Portos e aeroportos próximos a região, tem decretos publicados cujo conteúdo versava sobre a necessidade de tais

com dezoito horas com uma parada para descanso, geralmente, pela noite, retomando tal viagem no dia seguinte, até o local desta pesquisa.

${ }^{5}$ A partir de junho de 2018, foram realizadas instalações na aldeia Mapuera que possibilitaram a inserção na internet no local, permitindo assim, acesso as noticias de forma geral. No momento da pesquisa de campo a notícia que dominava os meios de comunicação em todo o mundo, era a pandemia do coronavirus.

${ }^{6}$ É necessário esclarecer que o retorno dos indígenas de várias cidades como Belém, Santarém e Óbidos, tornava a tensão em Mapuera mais presente entre profissionais de saúde, o autor do relato de experiência e os indígenas que ali estavam antes da pandemia, já que as mencionadas cidades já apresentavam casos da covid-19, inclusive números crescentes de mortes. Somado a esse contexto de insegurança, o cacique geral da aldeia estava em viagem por vários estados e, possivelmente, retornaria a Mapuera pelos dias seguintes.

${ }^{7}$ Essas cidades fazem parte do trajeto do transporte hidroviário na região, até a chegada na aldeia Mapuera.

${ }^{8}$ Por conta da situação que se apresentava, a equipe de saúde na Mapuera começa a receber instruções de permanência no local por mais dias para evitar contatos com outras pessoas fora da aldeia. Além disso, o método era: Quando sair da aldeia, o profissional deveria ficar em quarentena, em Oriximiná, até seu retorno para Mapuera. ${ }^{9}$ Há mais de 40 anos os indígenas da aldeia Mapuera foram evangelizados pela Igreja Protestante Batista. Desde então, a base religiosa do local se pauta nas diretrizes desse protestantismo. Assim, os cultos ocorrem dias de quarta e domingo, onde pode-se contar a presença de, aproximadamente, 200 pessoas em cada evento dessa natureza, em especial, aos domingos. (QUEIROZ, 1999; WAI WAI AWPEYASA, André; WAI WAI KOYON, Nelson; POTIGUAR JUNIOR, 2017). 
espaços serem fechados por quinze dias, no princípio de abril de 2020, evitando a circulação de pessoas e contágio pelo coronavírus.

A instabilidade se fez presente no campo tanto para todos nós, equipe de saúde, professores quanto para alguns indígenas. Notícias chegavam de que indígenas que desejavam adentar a aldeia Mapuera, foram proibidos de fazê-lo, inclusive o cacique geral, por ser desconhecido o estado de saúde deles. Após uma semana, com negociações frente ao Ministério Público; medição da temperatura e uma quarentena de sete dias, na cidade de Oriximiná, os indígenas e o cacique chegaram a Mapuera.

Diante do fato acima, decidimos ficar mais recolhidos e passando a entrevistar os indígenas no local onde estávamos instalados ${ }^{10}$. A tática que adotamos em campo não diminuiria a possibilidade de contrair o Covid-19, pois o contato com pessoas iria se fazer sem uma garantia de que elas não tivessem se aproximado dos recém-chegados. Mas dez dias se passaram e os ânimos se acalmaram, pois era o tempo suficiente para perceber a manifestação ou não da doença no local, frente a situação ali vivida. Felizmente nada ocorrera.

As notícias chegavam de forma rápida e todo o cuidado, até a duração da quarentena decretada inicialmente no país e no Pará, demonstrava que um inimigo oculto nos rondava. Isso fez com que a pressão familiar, relativo ao nosso retorno à Belém, crescesse. Mas a decisão já estava tomada: continuaríamos em Mapuera até meados de junho do corrente ano, que fora no prazo planejado para a execução dos estudos. Seguimos realizando a pesquisa de campo, tomando as precauções ${ }^{11}$.

$\mathrm{Na}$ Mapuera, por conta das restrições de deslocamentos, todos sabiam que nossa alimentação se escasseava, sendo impossível navegar pelo rio visando realizar compras de suprimentos alimentares na cidade sede. Receber ou enviar encomendas/alimentos, via avião, estavam proibidas por medidas protetivas da equipe de saúde do DSEI-GUATOC, convocados a ficar mais dias na aldeia. Com indígenas, trocas e doações foram acionadas: a cada carne de caça recebida, doávamos sal, açúcar e arroz e assim os intercâmbios tornaram-se constantes. Isso foi até o final de maio e início de junho de $2020^{12}$.

Com a instalação da pandemia no Pará e nas regiões próximas a Mapuera, realizamos palestras, rodas de conversas na escola local sobre a Covid-19, remédios caseiros e a importância do uso de limão para possibilitar o aumento da imunidade ${ }^{13}$ das pessoas, via a vitamina $\mathrm{C}$ que o mesmo possui.

\footnotetext{
${ }^{10}$ Durante dias em campo, podemos perceber que o cacique geral da aldeia Mapuera, desde de sua chegada, se colocou em quarentena, em sua casa, pelo menos dez dias. Quando de nossa saída da Mapuera, perguntamos ao mesmo: "Quando o senhor vai a Belém cacique? "Ele respondeu "Como fiz aqui, só vou com tudo estiver passado professô".

${ }^{11}$ No decorre desse contexto, surgem dois casos de malária na Mapuera, causando-nos incômodos, já que em aldeias próximas já havia ocorrido um surto dessa doença, deixando ainda mais frágil os indígenas dessa região.

${ }^{12}$ Para além da troca de alimento com os indígenas, ocorreram esses intercâmbios com a equipe de saúde. Nas refeições diárias, doávamos arroz e eles complementavam com feijão e carne e vice-versa, tornando possível nossos almoços e jantares.

${ }^{13}$ A ideia em fazer esse debate na escola, se dava pelo limão está em abundancia na aldeia, nesse período, mas pouco aproveitado, a ponto de perceber eles caídos no chão, até apodrecer. A partir dessa discussão, a adesão ao uso desse fruto fora visível, mostrando que ações simples como essa, podem fazer efeito, desde que a explicações e diálogos sejam numa linguagem acessível para compreensão de todos.
} 
Figura 2 - Campanha de incentivo ao consumo do suco de limão na língua Wai Wai.

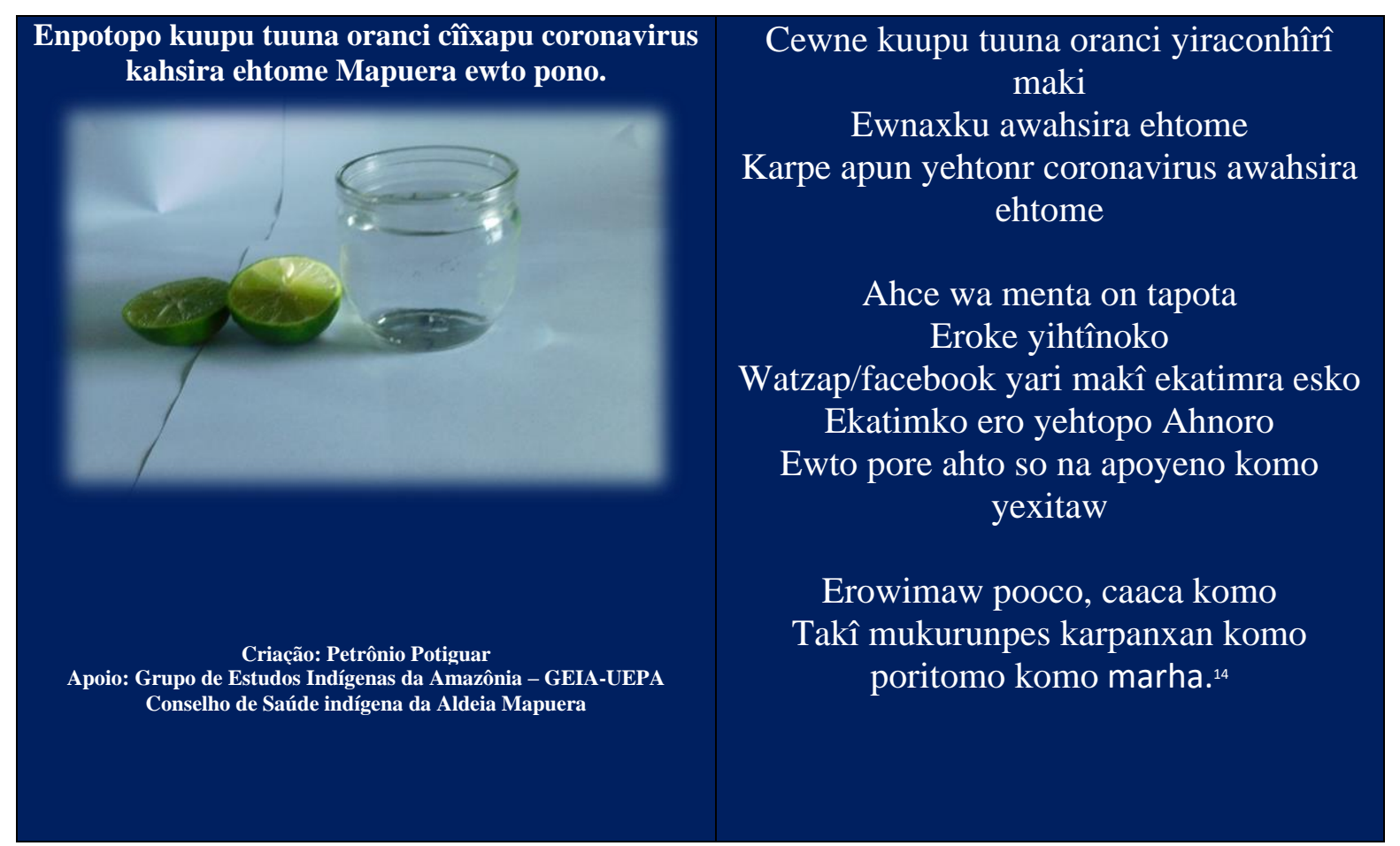

Fonte: Caderno de campo do autor/ março de 2020.

Nesse evento, elaboramos um material que fora demonstrado na escola e na igreja local e distribuído em grupos de Whatzaap na aldeia que chamava atenção para a importância de tornar o suco de limão para auxiliar no aumento da imunidade. Além disso, "tomar" o sol pela manhã, por conta da absorção de vitamina $\mathrm{D}$, dentre outros cuidados eram ações simples e de fácil adesão, mesmo que a longo prazo.

Após o evento acima, as aulas escolares, por decreto municipal, foram suspensas na aldeia, fazendo as pessoas se recolherem ainda mais. A partir desse momento a preocupação de todos era presente, pois a cada espirro e tosse ficávamos em alerta ${ }^{15}$.

Após anunciados casos de Covid-19 e óbitos, em Belém e Santarém ${ }^{16}$ e a determinação da quarentena nesses e outros municípios do Pará, 45 estudantes universitários indígenas que estudam nessas cidades, manifestaram retornar para Mapuera, instalando uma crise entre lideranças e a equipe de saúde, aprovando e desaprovando, respectivamente, essa entrada no local ${ }^{17}$.

\footnotetext{
${ }^{14}$ Tradução para o português: Com um copo de água e meio limão, você evita a gripe e deixa seu corpo mais resistente ao coronavirus. Se gostou dessa ideia, tome uma atitude, saia do WhatsApp e facebook e espalhe ela por toda aldeia que tenha parentes. Assim você pode salvar a vida de um velho (pooco), velha (caaca), jovens (karpamxan) e adultos (poritomo).

${ }^{15}$ Para registro, é bom chamar atenção que Mapuera sofre com constantes quedas de temperatura, ora estava quente, ora abafado ora frio, causando um desequilíbrio no organismo e alterações no corpo, possibilitando o surgimento tosses e febres, tornando a imunidade de indígenas e a nossa, ainda mais frágil. Além disso esses sintomas eram características da Covid-19, o que aumentava nossa insegurança.

${ }^{16}$ Todos os dias, menos as terças feira, há uma linha de transporte que sai de Santarém para Oriximiná, deslocando aproximadamente, de 100 a 200 pessoas em cada viagem, sendo que, 50\% desses passageiros tem destino final a cidade de Oriximiná.

${ }^{17}$ Notei que um dos motivadores para o retorno dos indígenas à Mapuera, além da vontade de estar perto da família, foi o anuncio de doação de cesta básicas pelo governo federal, desde que estivessem nas aldeias. Outra questão,
} 
O deslocamento dos indígenas para Mapuera, no ponto de vistas de alguns profissionais de saúde e indígenas, colocava em risco a população que estava ali, já que além de saírem de uma área de risco - Belém e Santarém -, não se sabia o estado de saúde desses agentes que pretendiam se deslocar para essa aldeia. Complementando esse quadro de fragilidade, grande parte dos indígenas que ali vivem ultrapassam a faixa etária dos 60 anos, chamados ali de poocos (velhos) e caacas (velhas) e muitos com comorbidades, como diabetes e asma. A crise se acirrou ainda mais ${ }^{18}$.

Com a presença do Covid-19 no Pará, ameaçando chegar na aldeia, se apresentava da seguinte forma para nós: estar na aldeia, possuíamos uma sensação de segurança, mas caso as vindas de indígenas para Mapuera, seja por medida judicial ou não, se concretizasse, tornaria nossas preocupações constantes. Por outro lado, seguir para Belém e Santarém, nos deparávamos com casos da doença e óbitos que aumentavam a cada dia. Estávamos diante do velho ditado popular: "Se correr o bicho pega, se ficar o bicho come!". A verdade é que nos encontrávamos no meio do "olho do furacão", o Covid - 19.

Todo esse contexto nos levou a seguinte pergunta: que papel, como antropólogo, poderíamos desempenhar diante da ameaça do "olho do furacão", o Covid-19, na Mapuera? Essa inquietação nos levou a iniciar diálogos com a equipe de saúde, representantes da igreja e da escola local e as lideranças, considerando que nos encontrávamos frente a vidas e histórias situadas e não meras estatísticas como se tornara as mortes nos noticiários internacional, nacional e local. Isso precisava ser olhado com sensibilidade e empatia (WAI WAI AWPEYASA; WAI WAI KOYON, POTIGUAR JUNIOR, 2019; SEGATA, 2020; ABA, 2020). Foi a partir dessa inquietação que iniciamos, juntos aos indígenas e lideranças nessa aldeia, a produção de um projeto de isolamento social para Mapuera. Vamos a uma ideia resumida dele ${ }^{19}$.

\section{ANTECEDENTES DO PROJETO DE ISOLAMENTO SOCIAL, EM MAPUERA, ENTRE OS INDÍGENAS "WAI WAI"}

Com receio da entrada na aldeia do "olho do furacão", via a inserção de indígenas oriundos de Belém, Santarém e Óbidos, articulamos uma reunião com o cacique geral, Conselho de Saúde local, lideranças, responsáveis pela igreja evangélica e pela única escola no local e a equipe de saúde, para expor perigos e possibilidades de contaminação em Mapuera, consequente da entrada desses agentes socias na aldeia.

Nas reuniões - no total de duas - presenciamos esclarecimentos da equipe de saúde; reclamações das lideranças indígenas referente orientações sobre a pandemia; cobranças do Conselho de Saúde de Mapuera frente a médicos, enfermeiros, Agentes de Saúde Indígena AIS e técnicos de enfermagem relativo a ações frente ao Covid-19.

\footnotetext{
segundo as "fofocas", era que um dos incentivadores da volta para aldeia, seria uma liderança contrário ao cacique geral, instaurando uma briga política nesse cenário dentro da aldeia.

${ }^{18}$ Após discussões, impedimentos e ações de movimentos contrários a essa entrada de indígenas na Mapuera, no Ministério Público Estadual, houve autorização dessa inserção, desde que eles cumprissem uma semana de quarentena em Oriximiná e, após esse contexto, se deslocassem para Mapuera.

${ }^{19}$ Nesse processo sempre estávamos em contato com a orientadora e numa dessas conversas, que nos colocava a par de toda a situação em Belém. No início, ela mencionava que o Covid-19 já estava "em todos os cantos" e que, supostamente estaríamos mais protegidos na aldeia. Ainda mais, a necessidade de ficar em campo pela dificuldade que teríamos em retornar, no futuro, já que a pandemia poderia durar muito tempo o que, de fato, alteraria todos os calendários de pesquisa. As atividades em universidades, museus; voos domésticos pelo estado do Pará, também foram cancelados a época. Estávamos "preso" ao campo e o campo a nós. A saída e permanecer na aldeia até passar o período crítico da pandemia, segundo a orientadora do autor desse relato, seria o caminho a seguir. E assim fora feito!
} 
Decisões foram tomadas, como a obrigatoriedade de a equipe de saúde atender os indígenas com máscara e o esboço do projeto de isolamento social, a partir da primeira reunião; um controle das lideranças diante da entrada de indígenas no local, na segunda reunião. Muitas questões ventiladas, mas, em nossa avaliação, poucas soluções tomadas ${ }^{20}$.

$\mathrm{Na}$ reunião, por duas vezes, pedimos a palavra para explicar algumas questões que tratasse da contaminação pelo Covid-19 até a internação em hospitais. Deixamos claro que, em caso de contaminação no local, a aldeia não possuía estrutura para esse tipo de demanda e que providencias deveriam ser tomadas, urgentemente, como o isolamento dos recém-chegados em Mapuera.

Após esclarecimentos, tínhamos inquietações sobre possibilidades da vinda de indígenas para aldeia e a percepção de que algo deveria ser feito de forma rápida e concreta ${ }^{21}$. As preocupações se fortaleceram quando, no dia seguinte a primeira reunião, perguntamos para um componente da equipe de saúde sobre esse primeiro encontro, a resposta fora desanimadora: "A impressão que tenho, é que estamos nadando contra a maré. Agora vou deixar as coisas acontecerem." $" 22$.

A partir da resposta dada, levamos três dias ininterruptos pensando em um projeto que tratasse da recepção aos indígenas que para essa aldeia se dirigissem em pleno pique de contaminação da Covid-19. Começamos a alinhavar um projeto de "Isolamento Social na Aldeia Mapuera" pautado nas experiências no local e nas condições que ali se apresentavam. Para tal, pedimos informações e discutimos com o cacique geral, Conselho de Saúde, lideranças, responsáveis pela escola e igreja evangélica local e a equipe de saúde. Constantemente, essa última era consultada para checar dados e assim ser inserido no processo de execução do mesmo.

Assim o projeto de isolamento social, revelou sua face particularizada e interdisciplinar, mostrando que ações dessa natureza e com povos indígenas, necessitam se pautar nesse perfil, isto é, em um processo dialogal, para que, de fato, tais inciativas sejam elaboradas e concretizadas tanto na teoria como na prática, considerando especificidades ali existentes. (BUCHELLET, 1989; LANGDON; GARNELO, 2004; SEGATA, 2020).

\section{UMA EXPERIÊNCIA FRENTE AO “OLHO DO FURACÃO”, O COVID-19: O RESUMO DO PROJETO}

Com uma equipe formada por indígenas e não indígenas, a proposta surgiu a partir da experiência de seus componentes, seja morando, trabalhando ou pesquisando na aldeia Mapuera. O propósito foi a orientação sobre o Covid-19 e a contextualização da prática do isolamento social temporário dos indígenas recém-chegados no local.

Para equipe reunida, era clara as dificuldades de se materializar o distanciamento social entre indígenas, em Mapuera, pela estrutura predial de suas casas, com um único

\footnotetext{
${ }^{20}$ Até esse momento, março e abril 2020, percebemos poucas ações do Distrito Sanitário Guamá-Tocantins-DSEI GUATOC, seja para a proteção da equipe de saúde e dos indígenas do local. Elas somente se fazem presente, pelos idos de maio e junho deste ano.

${ }^{21}$ Ao todo, ocorreram duas reuniões com a equipe de saúde e lideranças em Mapuera, cujo o tema era a Covid-19. Uma participamos e outra não. Mas redigimos as atas das duas reuniões - a última com base nas anotações de algumas lideranças - o que nos forneceu segurança para algumas afirmações aqui colocadas.

22 Dentre outras questões, o que incomodava os profissionais de saúde, era a falta de ação das lideranças no local, apesar da preocupação de algumas. A principal inquietação desses profissionais era o não cancelamento dos cultos na aldeia, um espaço de aglomeração de pessoas e potencial transmissor de qualquer doença, como o Covid-19. Além disso, era notório, na maioria dos indígenas, em Mapuera, o apoio a vinda dos estudantes que estavam na cidade de Belém, Santarém e Óbidos, e que para médicos, enfermeiros e técnicos em enfermagem não indígena, era uma irresponsabilidade. Por outro lado, esse retorno dos alunos-indígenas, aliviava a saudade e as preocupações de pais e avôs desses agentes sociais, em Mapuera. Daí o desanimo revelado no profissional de saúde.
} 
compartimento, inviabilizando qualquer tipo de isolamento que siga os protocolos do Ministério da Saúde - MS. Isso levou o grupo a pensar em alternativas que se apresentassem nesse local para possibilitar esse isolamento, exclusivamente para os que na aldeia chegavam ${ }^{23}$.

Apostamos no voluntariado dos indígenas no momento da chegada em Mapuera, a partir das orientações dada pela equipe de saúde às lideranças e fiscais na aldeia. A intenção era somar esforços para que esse isolamento ocorresse, pelos motivos aqui elencados. $\mathrm{O}$ papel das lideranças, fiscais, professores, pastores da igreja evangélica e de familiares, possuía importância crucial nesse momento, já que eles é quem tinham contato direto com os indígenas desejosos em retornar para esse local.

O projeto buscou aproveitar espaços já existente na localidade, bem como, otimizar esses lugares para promover os cuidados e prevenção por meio da quarentena/isolamento social frente a ameaça de Covid-19, a custo zero ${ }^{24}$.

Fora cogitada, parcerias com o DSEI/GUATOC, através das ações de médicos enfermeiros e agentes de saúde que já desenvolvem atividades no Posto Indígena de Saúde PIS, em Mapuera. Eles tão somente acresceriam em suas rotinas, as visitas aos locais de isolamento para monitoramento da pressão, oxigenação e temperatura.

A Secretaria Municipal de Educação de Oriximiná - SEMED, seria a parceira no fornecimento materiais de limpeza e alimentos, por intermédio do envio de merenda escolar ${ }^{25}$ a quem, por ventura, ficasse em quarentena na escola e outros espaços na comunidade cumprindo isolamento. A doação de cesta básica pelo governo federal, foi outra alternativa pensada para alimentação aos que nesses espaços se isolassem.

Outro objetivo, foi oferecer proteção e prevenção à população indígena local, em caso de necessidade de um isolamento social/quarentena forçada, aos que para essa aldeia se dirigem. Visava prevenir e acolher os indígenas idosos com suspeitas de gripe sintomática, diabetes, pressão alta etc. frágeis ao Covid-1926, evitando assim, a disseminação e o alarmismo na Mapuera, bem como, a perda de parte da história do lugar que se faz presente em suas memórias.

A primeira possibilidade de recepção dos indígenas recém-chegados, foi a Escola de Ensino Fundamental Wai Wai que estava com suas atividades suspensas por decreto municipal e estadual. $\mathrm{O}$ espaço se apresentava conforme as figuras abaixo:

\footnotetext{
${ }^{23}$ Esclarecemos que a recepção de indígenas que se deslocaram para Mapuera no período do "olho do furacão" o Covid-19, todos, por recomendação do Ministério Público Estadual, cumpriram uma "quarentena" de uma semana na cidade de Oriximiná para, em seguida, se deslocarem para Mapuera, segundo a informação do Responsável Técnico - RT pela Casa de Saúde Indígena CASAI de Oriximiná. Daí a necessidade de mais uma semana de isolamento na aldeia, para complementar esse ciclo. Pelo menos era essa a ideia central do projeto.

${ }^{24} \mathrm{O}$ custo zero considerava que os locais - escola, "Casa dos Professores" e dois alojamentos da Igreja evangélica, em sua maioria, estavam estruturados. Além disso, a parceria com a prefeitura municipal e outros pormenores ligados a ela, facilitavam o acesso a alimentos e materiais necessários para a manutenção e limpeza desses locais. Isso ficará mais claro nos parágrafos seguintes.

${ }^{25}$ É bom lembrar que a merenda escolar, por lei, já tinha sido prevista no orçamento anual das secretarias de educação para as escolas dessa região, dentre elas, as que compõe as áreas indígenas. Desse modo, mesmo com a suspensão das aulas, essa merenda, por lei, deveria ser oferecida para auxiliar familiares em tempos de pandemia, revelando ônus zero para Secretaria Municipal de Educação de Oriximiná, na elaboração e execução do projeto de isolamento já que, absolutamente nada, seria acrescido em seu orçamento anual. Isso era válido para possível necessidade de ações de seus funcionários que, exerciam a função como cozinheiro e serviços gerais, poderiam prestar serviços no período da quarentena.

${ }^{26}$ Havia o entendimento que, isolando os recém chegados, além de protege-los, protegia também os indígenas inseridos no grupo de riscos: idoso, diabéticos etc.
} 
Figura 3 - Escola Indígena Wai Wai. (Parte frontal)

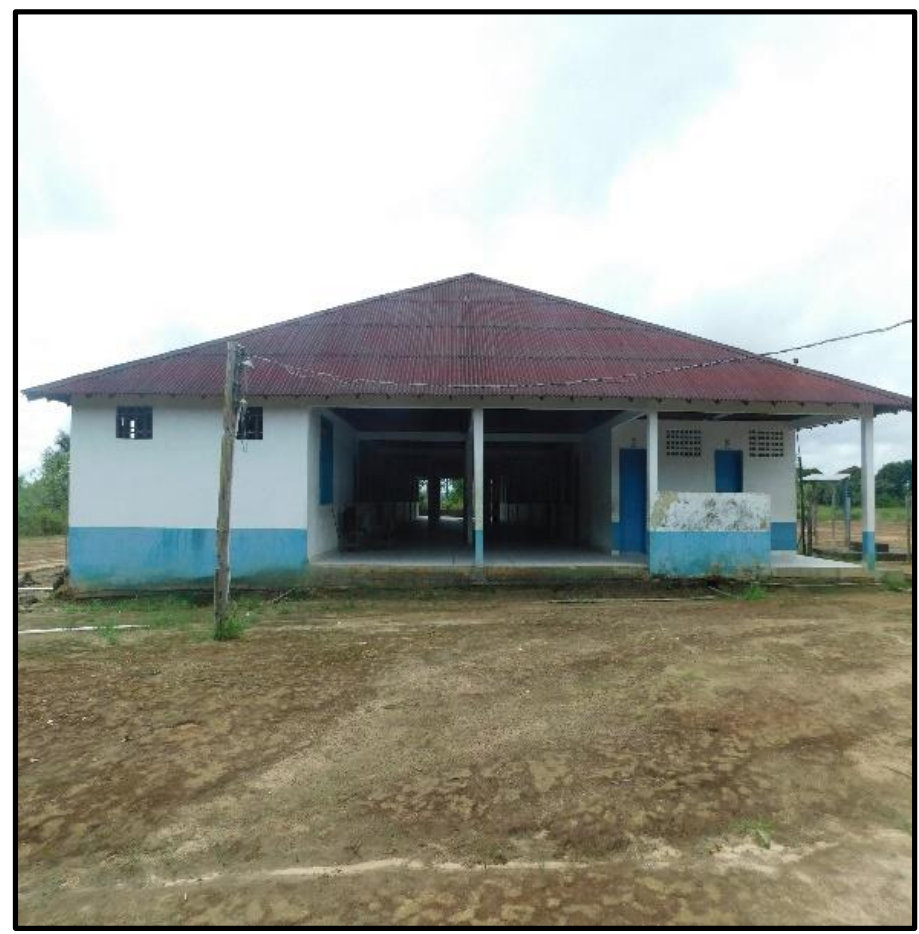

Fonte: Do autor/abril de 2020

Figura 4 - Escola Indígena Wai Wai. (copa cozinha)

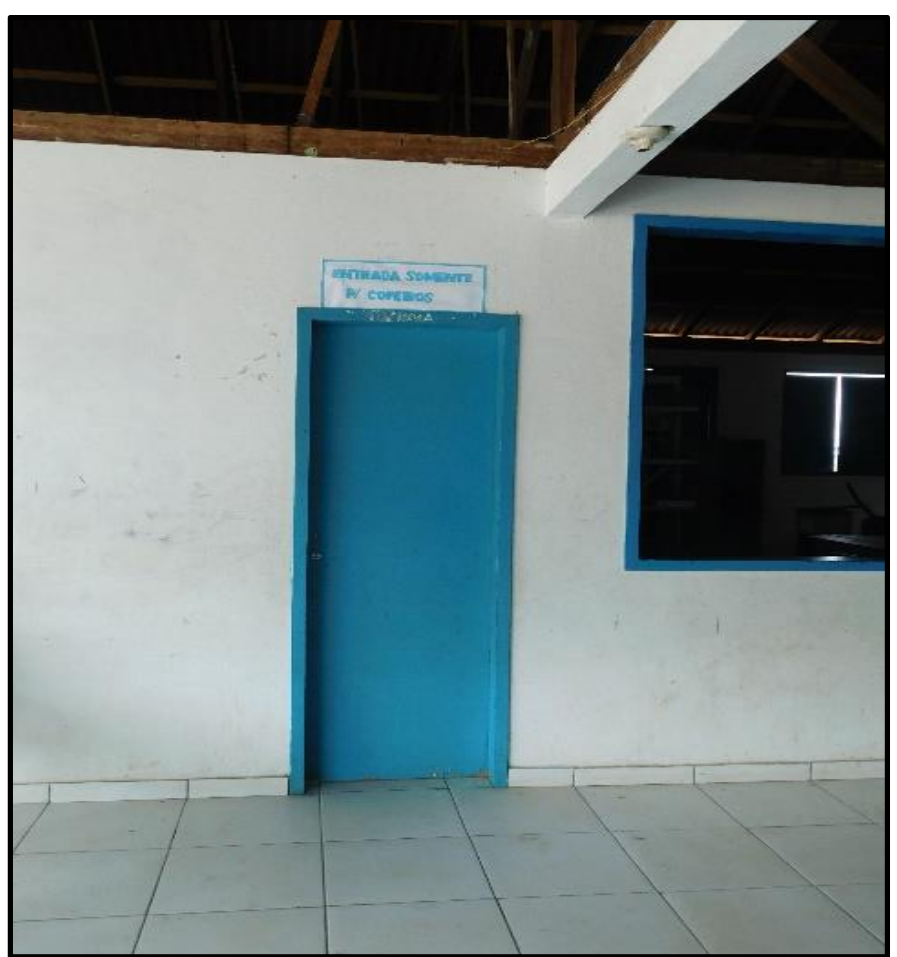

Fonte: Do autor/abril de 2020

Com 10 salas, o prédio poderia ser isolado e as salas compartimentadas, por divisórias de madeiras, transformando-os em 2 espaços em cada sala. Com essa estratégia, a escola acomodaria, num todo, 20 pessoas. Além disso, esse espaço possui uma cozinha que continha 
pratos, colheres, panelas, fogão e gás, além de uma estrutura para atar rede nas salas. Possuía moveis comuns como cadeiras e mesas que poderiam ser usados como suporte para todo apetrecho que os ocupantes deste espaço possuíssem. O local continha luz, água, banheiro, um freezer horizontal e wi-fi, o que impediria o isolamento total dos indígenas que para esse espaço fossem encaminhados, em especial, os mais jovens ${ }^{27}$.

Em caso de isolamento, a pessoa ficaria por 10 dias nos locais, com visitas programadas de parentes objetivando o fornecimento de alimentos (café, almoço e jantar). Após isso, se programariam visitas da equipe de saúde em três períodos: pela manhã, pela tarde e uma pela noite, visando o monitoramento dos indígenas como pressão, oxigenação e temperatura.

Outro local escolhido para servir de isolamento, fora a "Casa dos professores" que sem uso, nesse momento da pandemia, abrigaria 3 indígenas, adotando as mesmas estratégias usadas na escola local.

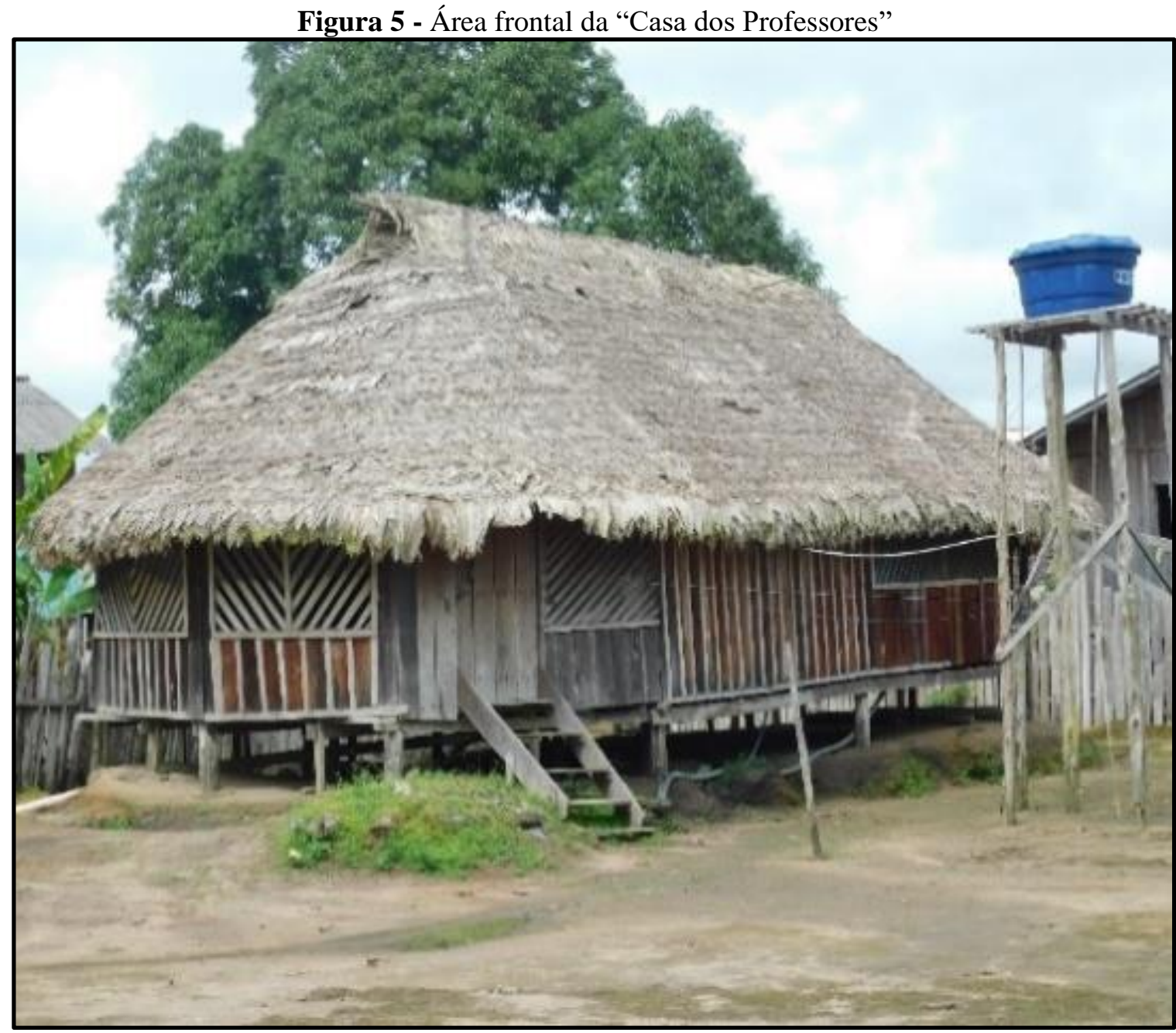

Fonte: Do autor/abril 2020.

\footnotetext{
${ }^{27}$ Destacamos que em julho de 2018, quando em campo, fora instalada a rede de Wi-fi na Mapuera, um dos pontos principais de sua transmissão, estava a escola aqui mencionada e a residência do cacique geral no centro dessa aldeia, próximo "Casa dos professores".
} 
Figura 6 - Cozinha da "Casa dos Professores"

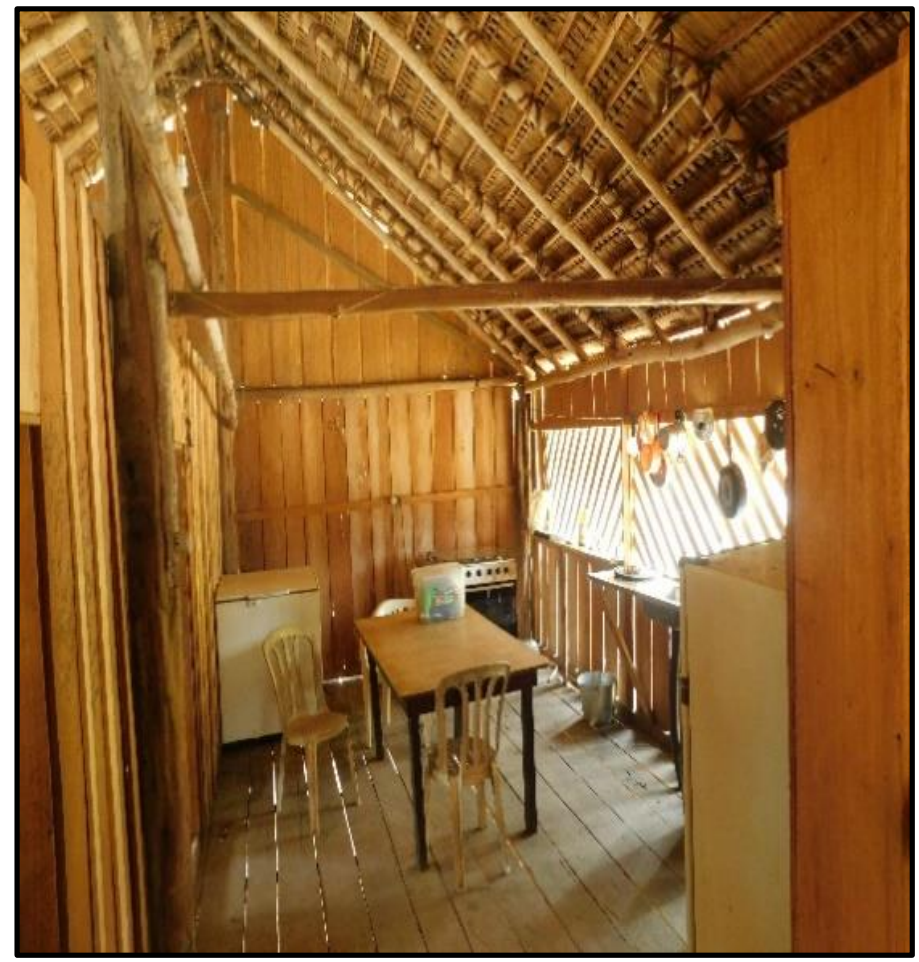

Fonte: Do autor/abril 2020.

"A casa do Professor" possui três quartos (figura 5), uma cozinha (figura 6), uma sala, um banheiro e acesso à internet, fornecida pela proximidade da casa do cacique geral. Há uma caixa d'água que serviria de apoio, com fornecimento de água. O procedimento de visitas iria se realizar da mesma maneira a adotada na escola Wai Wai, seja da família e profissionais da saúde.

Outros espaços pensados para recepção/isolamento dos indígenas que se dirigissem a Mapuera, foram dois alojamentos construído por conta do VIII Congresso Nacional das Lideranças Indígenas Evangélicas - VIII CONPLEI, em 2018, ao lado da igreja evangélica.

Figuras 7 e 8 - Alojamento próximo a igreja evangélica na Mapuera.
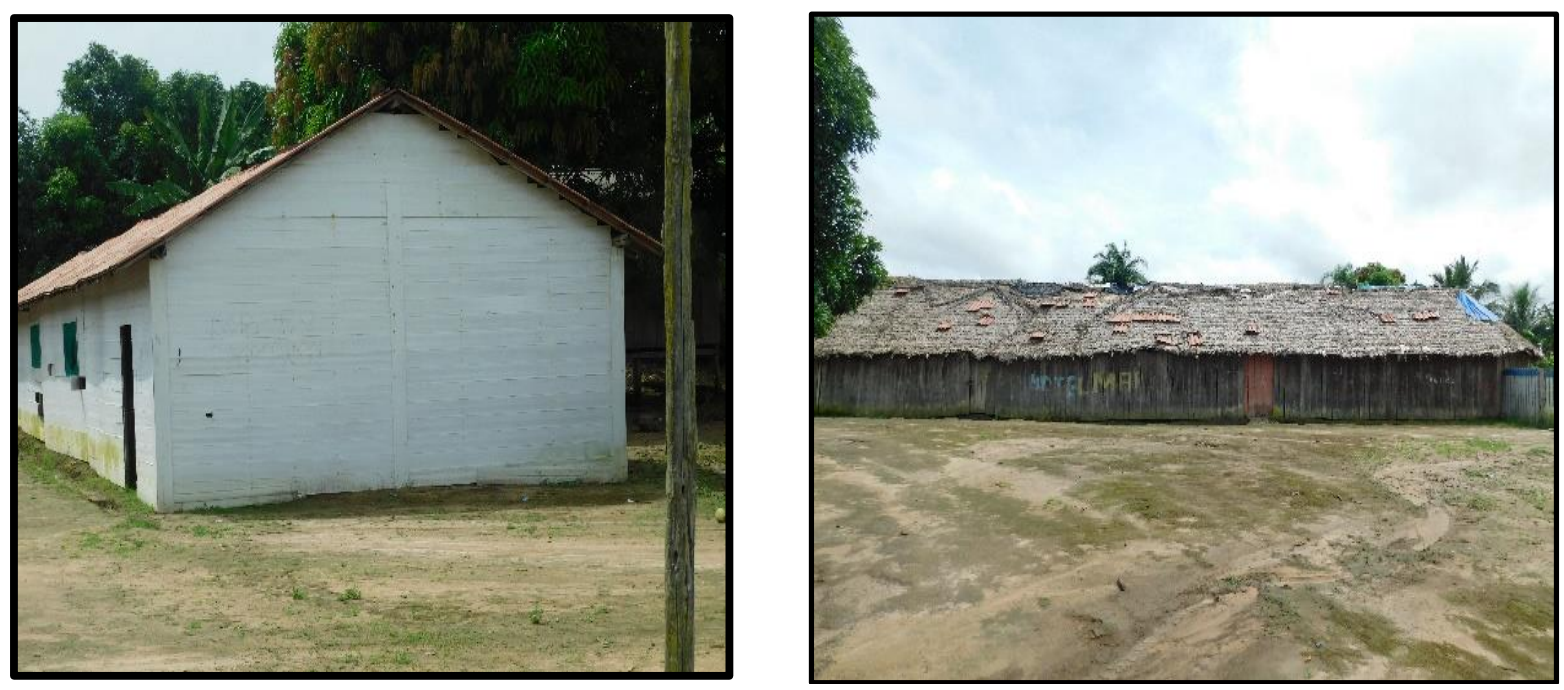

Fonte: Do autor/abril de 2020. 
Sem uso, esses locais como demonstram nas figuras 7 e 8 , foram alternativas para o isolamento pretendido. Os mesmos exigiriam reparos urgentes por não possuírem água encanada. Isso seria providenciado pelos Agente Indígenas de Saneamento - AISAN ${ }^{28}$, conforme acordado em reunião ${ }^{29}$.

As alternativas se apresentavam como forma de amenizar e tranquilizar os indígenas da aldeia e, ao mesmo tempo monitorar, os "parentes" oriundos de vários lugares com direção à Mapuera, evitando o surgimento e prevenção do Covid-19 e preservando a saúde mental e física do que ali vivem, mesmo que opiniões diversas sobre esse contexto existissem no local.

Nos lugares destinados ao isolamento dos indígenas, seriam tão somente permitidas visitas de familiares da forma que não expusessem esses visitantes, numa evidencia que o isolamento não requer aproximação física de familiares, amigos, irmãos etc. Elas se dariam da seguinte forma: 8:00-9:00 (Café); 12:00-13:00 (Almoço) e 19:00-20:00 (Janta) e seguindo todos os protocolos organizado pela equipe de saúde, em especial, o distanciamento.

As visitas dos profissionais de saúde se dariam para monitoramento de forma que as orientações médicas seriam realizadas por enfermeiros e AIS's. Isso se daria, considerando que as demandas cotidianas desses profissionais no PSI não seriam comprometidas. Nessa estratégia adotada, não alterava a rotina deles, já que o horários de visitação e monitoramento da equipe de saúde, sempre se dariam às 9:00-10:00; 15:00-16:00 e 18:00-19:00 hs, isto é, o momento de menos pico de atendimento no PIS e o revezamento entre eles, era viável, segundo fora planejado. ${ }^{30}$

Nesse projeto de isolamento, pensou-se em um mínimo de estrutura, que não alterasse e onerasse qualquer uma das secretarias envolvidas nesse processo, sejam de saúde ou educação, mas aproveitasse seus funcionários e serviços, sem desregular sua base salarial. Na escola, os funcionários com funções de cozinheiros, copeiros e vigias, seriam aproveitados, segundo negociações com a SEMED/Oriximiná, para que pudessem realizar seus serviços nesse espaço. Para isso seriam providenciados os devidos cuidados com sua segurança e saúde como o uso de máscaras, álcool em gel e distanciamento, foram pensados.

Já o DSEI -GUATOC como parceiro, entraria com a seguinte estrutura de pessoal: 01 médico; 01 enfermeira; 04 Agente de Saúde Indígena. Além disso, o da Secretaria Municipal de Saúde - SEMSA, seria acionado para a doação de materiais necessário para esse contexto visando a proteção dos profissionais de saúde e dos indígenas isolados.

Para garantir o processo de limpeza, atendimento, pensou-se em um mínimo de estrutura de higiene. Para isso a parceria com a SEMED e a SEMSA, visava manter o local limpo e em segurança no contexto do atendimento/monitoramento diário. Assim, a estrutura material foi desenhada: Máscaras de proteção (200); Álcool Gel (60 litros); desinfetante Kboa (60 litros); detergentes (60 litros); vassouras (04); rodos (04); luvas de proteção (20 pares); escapulas para armar redes (30). Isso visava atender os momentos emergenciais desse isolamento.

De todo modo, o cuidado e a prevenção, foram caminhos para que, mesmo estando em uma curva crescente da pandemia, necessário se fez ter prevenções, evitando aproximação, contaminação e disseminação pelo "olho do furacão", o Covid-19, na aldeia Mapuera, onde se

\footnotetext{
${ }^{28}$ Alertamos que qualquer atividade de caráter emergencial, a mesma é acionada por meio de reunião com lideranças, que convoca indígenas para a busca de madeira na mata ou de qualquer material para construção de abrigos etc, o chamado mutirão. Percebemos que em pouco tempo, com esses mutirões, eles conseguem construir determinados espaços e realizar diversas atividades, em tempo recorde.

${ }^{29}$ A cisterna de fornecimento de água em Mapuera, está instalada a uns vinte metros desses alojamentos, o que facilitava reparos e instalações urgentes referente ao fornecimento de água. Relativo a energia, essa seria uma extensão da igreja evangélica, já que ela estava localizada ao lado desses alojamentos.

${ }^{30}$ As visitas de familiares e da equipe de saúde para realização de monitoramento, foram pensadas de forma diferente, para evitar acumular pessoas no local. Por isso o tempo uma hora para visita da família depois a entrada da equipe de saúde, tornando-se forma mais adequada para esse contexto.
} 
centrou essa proposição ora apresentada. Caso progredisse a pandemia e o isolamento, novas formas estruturais deveriam ser pensadas junto aos parceiros e as equipes aqui mencionados, pois a saída do autor da Mapuera e desse relato de experiência, seria iminente, como de fato ocorreu.

\section{CHEGANDO AO FIM: O QUE OCORRERA APÓS A PRODUÇÃO DO PROJETO DE ISOLAMENTO SOCIAL?}

O projeto "Isolamento Social na aldeia Mapuera" foi entregue ao cacique geral e a equipe de saúde. Dias depois, barulhos de motores de lanchas e canoas, pela noite, madrugada e durante o dia, foram ouvidos, anunciando a chegada de indígenas no local em final de abril e início de maio de 2020. O quantitativo deles - os recém chegados - perfaziam um total de, aproximadamente, 45 (quarenta e cinco).

Estarmos diante de 45 indígenas oriundos de vários lugares onde o Covid-19 estava em pleno pico, nos assustou e tirou a concentração para a realização de pesquisa. Decidimos nos isolar em casa escrevendo relatos e materiais para a tese. Assim teríamos menos exposição e riscos, mas sempre atentos ao uso ou não do projeto de isolamento social.

Os indígenas, de forma geral, estavam divididos em suas opiniões sobre essa chegada e posterior isolamento, uns preocupados outros não. $\mathrm{O}$ uso de máscaras e procedimentos necessários para evitar a contaminação, ainda não era percebido em Mapuera, até mesmo porque, em todo o Brasil, os protocolos e cuidados necessários com uso de álcool em gel e máscaras, ainda eram tateante no país, e muito incipiente nos lugares distantes nesse período inicial da Covid-19, pelas incertezas que esse vírus e essa doença traziam.

Quinze dias se passaram e era notável a circulação dos recém-chegados na aldeia. O tamanho de nossa preocupação era a dimensão da despreocupação de alguns indígenas frente ao Covid-19. Isso se dava pela quarentena que eles tinham passado na cidade de Oriximiná e a fé em Deus: "Nós aqui, tamo protegido dessa doença. Se morre, agradece pro estar perto de Jesus. Se viver agradece por permanecer vivo. Mas a aldeia tá protegida".

E o projeto de isolamento social? A crença de que nenhum dos indígenas chegados na aldeia, não eram potenciais transmissores do Covid-19, era maior nas lideranças e no cacicado do que em nós. Até esse momento, o projeto não fora executado. O desejo era que realmente ele não fosse usado, pois não sendo utilizado e, parecendo contraditório, ele estaria dando certo, pois apontaria que nenhum infectado teria adentrado em Mapuera.

Informamos aqui que os protocolos sugeridos pelos Ministério da Saúde e OMS, sob a ótica técnica, faltou ser mais detalhados, já que a ideia inicial era uma "proposta" emergencial, o que suscitava adequações futuras. Mesmo assim e da forma como fora finalizada, o projeto atendia as necessidades urgentes que o contexto pedia. A partir desse momento, percebemos que era hora de sair de campo junto a equipe de saúde, cuja a troca iria ser feita em meados de junho de 2020.

É necessário esclarecer que o projeto de isolamento social foi compartilhado com DSEI GUATOC e, segundo informes posteriores, soubemos que o mesmo não iria aderir a tal proposição, não se sabe por que motivos. Mas um mês depois do retorno para Belém, na primeira quinzena de junho, esse DSEI, lançou um projeto de proteção aos indígenas e profissionais da saúde que atuam nessa aldeia frente ao Covid-19 e nele percebi que linhas do mesmo possuía "semelhanças" do que foi aqui apresentada.

Não importa que motivos da não adesão ao projeto aqui apresentado pelo DSEIGUATOC, mas sim compreender que ele fora feito sob várias mãos e pensando na particularidade do local. Além disso, saber que a proposição aqui apresentada, serviu de inspiração a projetos institucionais do governo federal, nos deixou confortável, por ver que as ideias do cacique geral da aldeia, do Conselho de Saúde local, da equipe de Saúde da Mapuera, 
do diretor da Escola Wai Wai e professores, do representante da igreja evangélica e do autor desse relato experiência, auxiliaram o DSEI-GUATOC na construção de políticas públicas em um momento tão difícil, no enfrentamento do "olho do furação, a Covid-19, nesse local.

Essa experiência revelou, a necessidade de um debate múltiplo para enfrentar o Covid19 e que os antropólogos e a antropologia, dentre outras áreas do conhecimento, sozinhas, não materializam projetos dessa natureza se não for dialogal, interdisciplinar e partilhado com os principais envolvidos nesses contextos, os povos indígenas na Amazônia. (BUCHILLET, 1989; WAI WAI AWPEYASA; WAI WAI KOYON; POTIGUAR JUNIOR, 2019).

Ainda mais, compreendemos que a experiência, respondeu a principal questão que nós fazíamos durante a pesquisa de campo relativo ao papel do antropólogo num contexto pandêmico. Não só respondeu como impulsionou a proposição desse projeto de isolamento social na certeza de a empatia, o respeito às diferenças, são bases para experiências como essa e acreditando que o "olho do furacão", o Covid-19, não se trata de apenas de "uma gripezinha", mas sim de um vírus letal que se não for enfrentado com responsabilidade e empatia, tornar-seá - se é que já não se tornou - arma principal para um genocídio e etnocídio que assola/assolará os povos indígenas, cuja vulnerabilidade é clara e latente.

Para esclarecimentos finais, em 30 de junho de 2020, a cidade sede da Mapuera, Oriximiná, registrava 10 casos suspeitos, 1.712, casos confirmados, 28 óbitos, 29 internados, 1.732 em isolamento. Mas 1.709 casos descartados, 1.399 curados. Nenhum caso dentro da aldeia Mapuera ${ }^{31}$.

Hoje, 15 de abril de 2021, momento de fechamento desse texto, a cidade de Oriximiná conta com 8.142 mil casos, 5.633 descartados; 25 internados, 7.252 recuperados, 1.309 em isolamento e 153 óbitos $^{32}$.

O que chama atenção é que, em menos de um ano, a cidade sede da Mapuera, Oriximiná, teve um aumento de aproximadamente $400 \%$ de casos confirmados e aproximadamente $500 \%$ de óbitos. Por outro lado, em Mapuera, temos notícias de 3 óbitos, e alguns casos de Covid-19, embrionários.

Os dados de Oriximiná, como município, estão postados no site oficial dessa prefeitura, não especificando as populações indígenas. Além disso, está em curso o processo de vacinação que tem no município 5.618 de vacinas aplicadas, sem especificar os indígenas. Em Mapuera, onde a vacina também está em curso, surgem problemas graves de negacionismos, fruto de fake news espalhadas entre eles, via Facebook e WhatsApp - e que causa preocupação constante nas lideranças nesse local, mas isso, são objetos para análises e produções posteriores.

Por fim, acreditamos que tudo isso vai passar!

\section{REFERÊNCIAS}

ABA, Associação Brasileira de Antropologia. As ciências sociais e a saúde coletiva e a atual epidemia da ignorância, irresponsabilidade e má fé. Disponível em:

http://www.portal.abant.org.br/2020/03/26/manifestacoes-da-aba-sobre-o-coronavirus. Acesso em: 1 abr. de 2020.

BUCHILLET, Dominique (Org). Medicina tradicional e medicina ocidental na Amazônia. Museu Paraense Emílio Goeldi. CEJU.UEPA. Belém, 1989.

BOLETIM CORONAVIRUS (COVID 19) ORIXIMINÁ. Disponível em https://www.oriximina.pa.gov.br/. Acesso em: 15 abr. de 2021

\footnotetext{
${ }^{31}$ Disponível em: https://www.oriximina.pa.gov.br/. Acesso em: 15 de abr. de 2021.

${ }^{32}$ Disponível em: https://www.oriximina.pa.gov.br/. Acesso em: 15 de abr. de 2021.
} 
BRASIL. Pátria Vacinada. Disponível em: https://coronavirus.saude.gov.br. Acesso em: 30 de mar. 2021.

CARDOZO, Ivaneide Bandeira e VALE JUNIOR, Israel Corrêa do (Orgs). etnozoneamento da porção paraense das terras indígenas Trombetas Mapuera e Nhamundá- Mapuera. Porto Velho- RO, EDUFRIO. 2012.

LANGDON, E. e GARNELO, L. (org). Saúde dos povos indígenas: reflexões sobre a antropologia participativa Rio de Janeiro. 2004.

QUEIROZ, Rubem Caixeta de. A saga de Ewka: epidemias e evangelização entre os Waiwai. In: Transformando os Deuses- múltiplos sentidos de conversão entre os povos indígenas no Brasil. Organizado por R.M. Wrigth. Campinas; editora UNICAMP, 1999,255284.

QUEIROZ, Rubem Caixeta e GIRARDI, Luisa Gonçalves. Dispersão e concentração indígena nas fronteiras das Guianas. Analise do caso Kaxuyana. In: Revista Brasileira do Caribe. São Luis, MA, Brasil. Vol XIII. Numero 25, Jul-dez-2012.

QUEIROZ, Rubem Caixeta. Trombetas- Mapuera: território Indígena. Brasília. FUNAI/PPTAL, 2008.

SEGATA, Jean. Covid-19: escalas da pandemia e escalas da antropologia. In: Notícias. Disponível em: https://www.ufrgs.br/ifch/index.php/br/covid-19-escalas-da-pandemia-eescalas-da-antropologia. Acesso em: 20 de jun. de 2020.

WAI WAI AWPEYASA, André; WAI WAI KOYON, Nelson; POTIGUAR JUNIOR, Petronio Lauro Teixeira. Conhecimento e uso das plantas medicinais entre indígenas: uma experiência educacional na Amazônia. In: A medicina tradicional popular amazônica (MTPA) e temas afim. Organização Rosineide da Silva Bentes. Serie Vidas. Editora CRV. Volume I. Curitiba, 2019. 